\title{
TITLE:
}

\section{ZENetic Computer: Exploring Japanese Culture}

$\operatorname{AUTHOR}(\mathrm{S})$ :

Tosa, Naoko; Matsuoka, Seigow

CITATION:

Tosa, Naoko ...[et al]. ZENetic Computer: Exploring Japanese Culture. Leonardo 2006, 39(3): 205-211

\section{ISSUE DATE:}

2006

URL:

http://hdl.handle.net/2433/250238

\section{RIGHT:}

(c) 2006 Massachusetts Institute of Technology; 許諾条件に基づいて掲 載しています。 


\author{
Naoko Tosa \\ and Seigow Matsuoka
}

A B S T R A C T

The

he authors present ZENetic Computer as a means of cultural translation using scientific methods to represent essential aspects of Japanese culture. Using images-deriving from Buddhism and other Asian concepts, sansui (landscape) paintings, poetry and kimonosthat have not heretofore been the focus of computing, the authors project the style of communication developed by Zen schools over hundreds of years into an exotic computing world that users can explore. Through encounters with Zen koans and haiku, the user is constantly and sharply forced to confirm his or her selfawareness for purposes of the story. There is no one right answer to be found anywhere.
Human communication is fostered in environments of regional communities and cultures and in different languages. Cultures are rooted in their unique histories. Communication media such as writing, music and film have developed to circulate these cultural characteristics [1]. Now, as the computing society spreads across the planet, computers must enable local and global cultures to communicate clearly and accurately. To that end, it is also necessary for those involved in computer technology to bring to life within the medium of computers local cultural ways of thinking.

In the research in intercultural communication from the perspective of engineering, there has been only one experiment in intercultural collaboration via machine translation [2]. This experiment found machine translation to be effective in cross-cultural collaborative research and development. Also, research into system design using an agent for intercultural communication in cyberspace [3] has produced a very interesting finding: that users' level of intimacy rises and communication becomes smoother if the agent breaks cultural taboos. For example, the use of slang words tends to elicit emotional response from users.

The above research is practical as a means of identifying characteristics latent in intercultural communication. However, in the extraction of these universal aspects, local communication aspects must be ignored in the process. Deep communication may actually be included in local cultural memories and symbols, but technological research into its expression and communication methods has yet to be pursued.

For intercultural communication research, in order to pursue local ethnic methods of expression and communication, and with backgrounds in editorial engineering [4] and art and technology [5] as a foundation, we researched methods for

Naoko Tosa (educator), Kyoto University, Academic Center for Computing and Media Studies, South Building 2F, Yoshida Nihonmatsu-cho, Sakyo-ku, Kyoto 602-8501, Japan. E-mail: <tosa@mm.media.kyoto-u.ac.jp>.

Seigow Matsuoka (laboratory director), Editorial Engineering Laboratory, 7-6-64 Akasaka, Minato-ku, Tokyo 107-0052, Japan. E-mail: <matsuoka_associates@eel.co.jp>.

Solicited by Julien Knebusch. integrating nonverbal informatio legories with verbal informatior to guide the user through a storybased narrative interaction, we decided to pursue the possibilities of digital storytelling [6].

In the traditional relationship between culture and computers, advances have been made in the recording of decaying traditional cultures in digital archives [7], restoration of artifacts and computer graphics simulations recreating lost ruins [8]. In order to create a system that can reproduce the cultural stories that lie within us, we decided to research a method for interactively expressing the previously unquantifiable essential characteristics of culture within peo-

Fig. 1. The interaction and context generation process. (C) Seigow Matsuoka and Naoko Tosa)

\section{Flow}

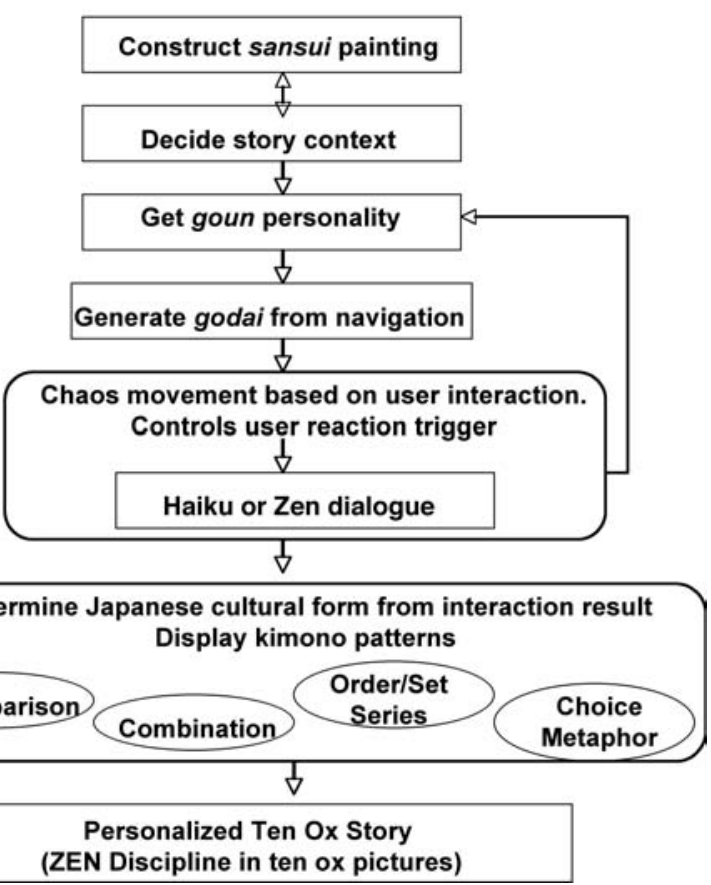




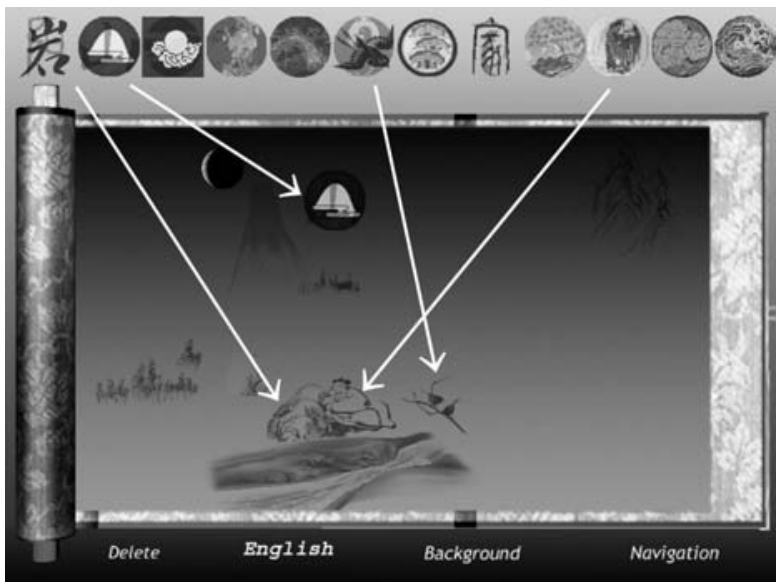

Fig. 2. Insert any 2D icon and construct a 3D sansui painting. (๑) Seigow Matsuoka and Naoko Tosa) This composition illustrates the context structure of haiku and Zen dialogue.

ple-for example, subjectivity, feeling, emotion and cultural personality-by integrating nonverbal and verbal information. Furthermore, we produced a storytelling method reflecting differences of emotion, consciousness and memory indispensable in the future communication abilities of computers.

As intercultural communication is a very broad field, in order to produce a specific example, one must pick up a single historic and cultural image and use that as a basis for building a real system. In this case, we chose Zen, one of the paths of Buddhism, and developed ZENetic Computer as a system in which people can virtually experience Zen culture.

\section{The ZENetic Computer Artistic Concept}

ZENetic Computer was developed as a specific example of intercultural communication. We focused on the roots of our native Japanese culture, including Buddhism, kanji, waka (Japanese short poetry) and haiku [9]. We decided to focus especially on the unique communication space and imaging method created by Zen and sansui (landscape) ink painting. A user of ZENetic Computer experiences the following scenario. First, the user builds a three-dimensional sansui ink painting on the display using an intuitive and easy-to-use interface, constructing her own virtual space.

The images used in this interface express the conceptions of nature and philosophy that characterize the history of Japanese Zen Buddhism, providing the user with a dramatic experience very different from the images of modern life [10]. Thus, in the introduction, the system brings about a kind of awakening within the user and encourages her unconscious imagination.

Next, as the system classifies the state of the user's consciousness based on the user's design of the sansui landscape, it generates a story appropriate to the user, drawing her through the display and into this alternate world.

In the story we include mechanisms meant to stimulate the user's consciousness developed from haiku and Zen rid- dles (koan). The story built from these elements is not a complete linear story like those found in movies or novels, but rather a nonlinear collection of short story fragments. A user who experiences these inconclusive story fragments feels a kind of uncertainty and holds an expectation and desire to connect these fragments and build a complete story. Because of this desire, the user may feel some hesitancy in being asked questions without a "correct" answer, but she cannot help but try to answer these questions.

Through several such compelling events, the user connects these stories and builds her own unique narrative. Next, as the user uses a virtual brush, a rake for the rock garden and other tools in response to questions posed by the system via images and voice, the door to the realization of her consciousness begins to open further. As the user's desire to connect the story fragments mixes with the system's user interface, the distance between her everyday self and true, hidden self begins to shrink.

$M a$ interaction plays an important role in the process of fusing these two selves. Ma is a very Japanese concept; it entails an emphasis on ephemeral events-the here-and-now within every experience.

Having thus traveled through several stages and scenes, at the end of the trip the user converses with a bull, an interaction used in Zen as a metaphor for expressing one's true self. Through this dialogue, the user can experience a process through which the everyday self and the subconscious self fuse together and bring about a unified selfconsciousness.

As the environment surrounding the system plays a very important role in the user's experience, we decided to create an Eastern atmosphere for the ZENetic

Fig. 3. Navigation of a sansui picture via 3D compass and Zen dialogue interaction with the rock garden interface. (C) Seigow Matsuoka and Naoko Tosa)

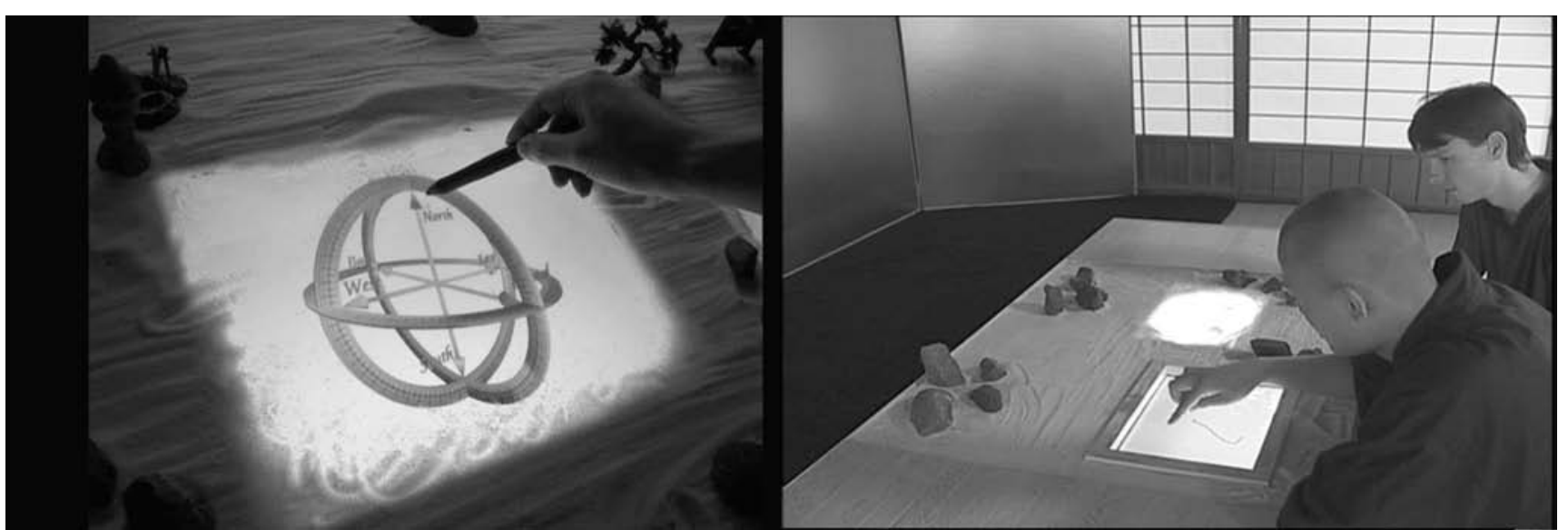



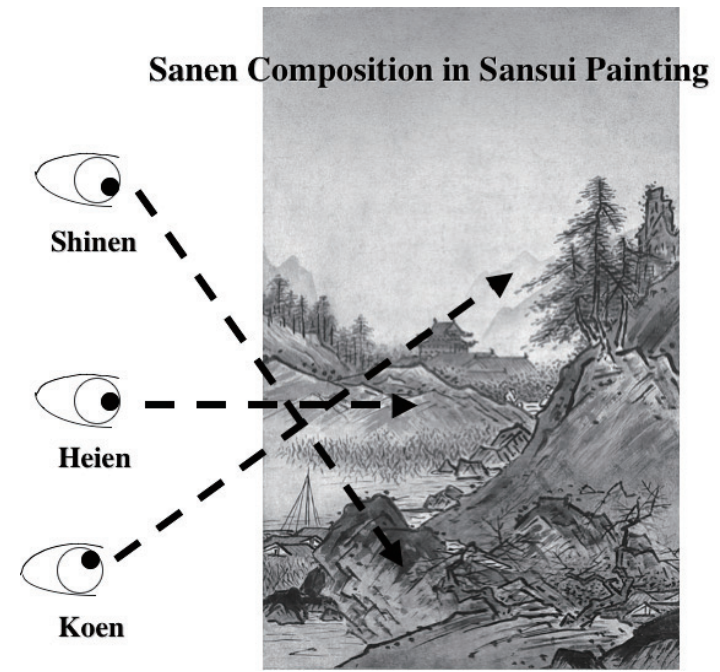

Fig. 4. Composition of sanen perspective in a sansui painting. (@ Seigow Matsuoka and Naoko Tosa)

\section{Relationship of Position and Distance within 3D Space}

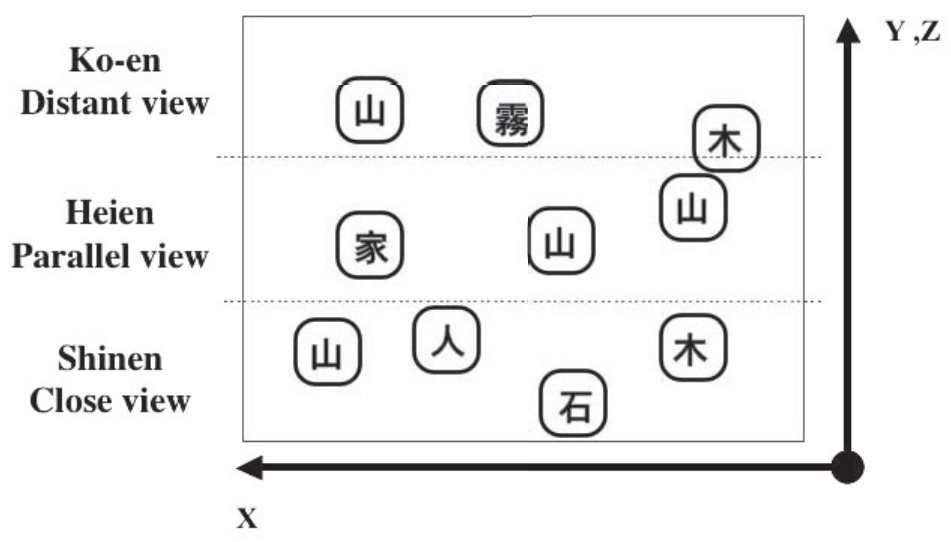

Fig. 5. Layout and distance within 3D space. (๔ Seigow Matsuoka and Naoko Tosa)
Computer installation through the use of calligraphic paintings, music and a low table (Color Plate F).

\section{THE FLOW OF THE \\ STORY EXPERIENCE WITHIN SANSUI SPACE}

The user walks through a story as follows (Fig. 1).

1. Generation of a sansui painting: The user selects a 2D hieroglyphic icon and drags it onto a virtual canvas. The $2 \mathrm{D}$ icon then changes into a 3D sansui object (Fig. 2). When the user finishes the sansui painting and selects the "Navigation" icon on the screen, the user can enter into his or her own 3D sansui picture using the 3D compass interface (Fig. 3).

2. Generation of haiku based on sansui icon composition: Each 2D hieroglyphic icon is associated with a haiku or Zen dialogue with a similar or related meaning. A haiku is generated according to how the 2D icon is selected and composed.

3. When the user approaches objects in the sansui painting, one of four associated Zen dialogues appears. For example, when the user approaches a river, the computer rec- ognizes the meaning "water," and the Zen dialogue "The Catfish and Gourd" appears.

4. Depending on which of the dialogues is generated, a form matching the user's personality is assigned one of the following four Japanese cultural forms:

- Kisoi: comparative design

- Mitate: choice and metaphor

- Awase: design in pairs

- Soroe: design based on sets

Depending on the results of all the user's Zen dialogue interactions, a Yuzen kimono pattern [11] is then selected.

5. In conclusion, a "Ten Ox Story" (10 steps leading to enlightenment) corresponding to the user's interactions is displayed.

\section{GENERATION OF THE SANSUi PainTing}

\section{Composition of 2D}

\section{Hieroglyphic Characters}

We divided sansui painting into $12 \mathrm{hi}$ eroglyphic characters (rock, mountain, moon, traveler, bridge, bird, tree, flower, wise man, cloud and water) and prepared 2D icons symbolizing each of them. Hieroglyphic characters are a precursor of kanji. These icons are the basic material of sansui painting. Each 2D icon is con- nected to a 3D computer-graphics object. When the user drags any 2D icon and constructs a personalized 3D sansui painting, a 3D pixel map is overlaid onto that position. Figure 2 is an example of a user-constructed sansui painting.

\section{Sanen Perspective in Sansui Painting}

As can be seen in the sansui painting in Fig. 4, there is a unique perspective scheme in sansui paintings called sanen. There are three perspectives within a sansui picture: koen, far away and viewed from below; heien, viewed straight on; and shinen, near and viewed from above. Depending on the position of the user's icons, graphics corresponding to the sanen area are displayed, increasing the realism of the user-created sansui painting. Each icon is categorized as koen, heien or shinen. Figure 5 shows part of a computer-recognized sanen composition and distance within 3D space.

Generation of Haiku and Zen Dialogue from the Layout of the Sansui Icons

When the user finishes creating the sansui painting, she can walk through the $3 \mathrm{D}$ sansui space she created by operating a $3 \mathrm{D}$ compass in the rock garden interface

\begin{tabular}{|c|c|c|c|}
\hline \multicolumn{3}{|c|}{ Icon Priority } & \multirow{2}{*}{$\begin{array}{l}\text { Haiku Output } \\
\text { The day passes slowly; A pheasant comes down onto the bridge. }\end{array}$} \\
\hline Bridge & Bird & House & \\
\hline Mountain & Moon & Cloud & The rift in the clouds, whence snow falls on the distant mountains. \\
\hline Water & Cloud & Rock & Advancing through pebbles, there flows a rivulet running from a spring. \\
\hline Moon & House & Water & An old quiet pond A frog jumps into the pond Splash! Silence again \\
\hline Moon & Traveler & House & The autumn moon; I wandered round the pond all night long. \\
\hline
\end{tabular}




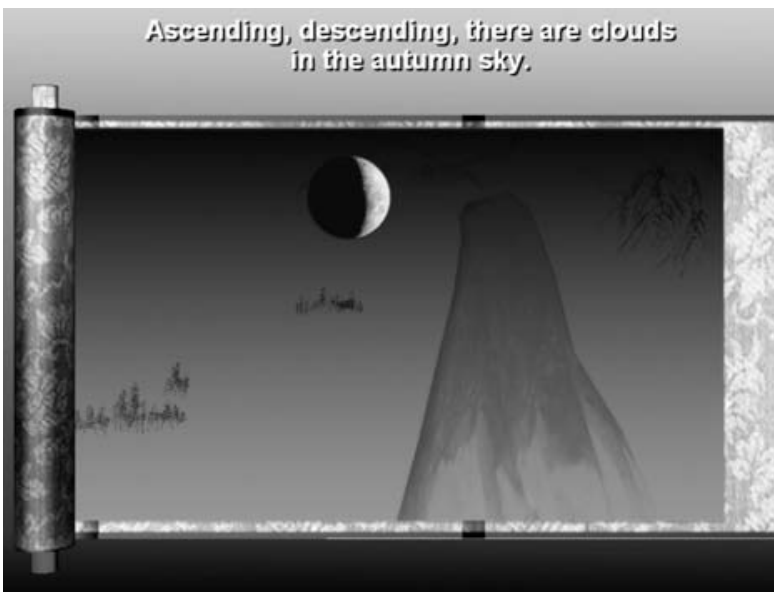

Fig. 6. Framing of "mountain" and "moon" icons and an example of generated haiku. (๔) Seigow Matsuoka and Naoko Tosa)

Fig. 7. Zen dialogue "Dharma Anjin," where the user draws herself using the touch screen. (๔) Seigow Matsuoka and Naoko Tosa)

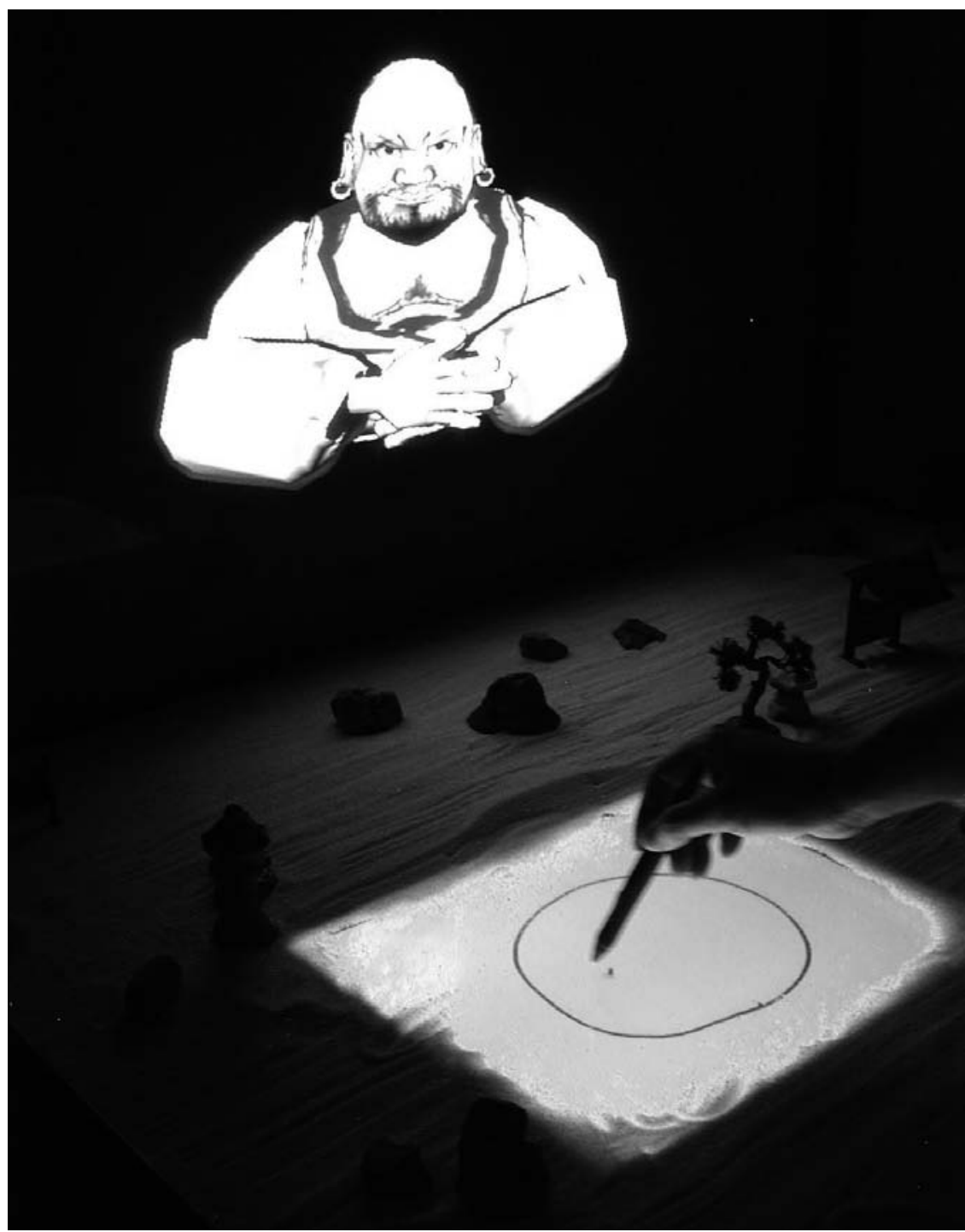

bearing an embedded touch screen (see Fig. 3). As the user approaches any sansui painting icon within the space, a haiku poem or Zen dialogue is output based on the combination of sansui painting icons contained in the framed display, as shown in Table 1. Figure 6 shows the framing of the "mountain" and "moon" icons, as well as a generated haiku example.

\section{Interaction Using \\ a Buddhist Human \\ Recognition Model}

Buddhism, which has been followed for over 1,400 years, has developed a method of interaction between master and pupil for creating deep understanding between people. We applied part of this method as an interactive model for the system. Interaction based on such a deep understanding is an area not yet researched by Western science.

\section{Sansui World Expression Based on the Godai Model}

In Buddhism, the directions and the go$d a i$, or five elements (sky, water, fire, wind and earth) that compose the world, are closely related. As the user explores the sansui world, changes in the weather based on the godai occur depending on the direction of movement. For example, if one goes north, it snows (connoting earth); south, thunder appears (fire); east, fog appears (wind); and west, it rains (water).

\section{Classification of \\ User Personality}

Buddhist thought holds that five basic physical and mental elements, or goun, make up the world; in this interactive system, we apply these elements in the classification of personality. The five personality categories are as follows:

- 色 (Siki)-One's personality focuses on nature and materials that actually exist

- 受 (Jyu)—One's personality focuses on intuitive impression

- 想 (Sou)—A focus on perceived visual images

- 行 (Gyou)-A process of mind that activates behavior

- 識 (Shiki)—A deep spiritual function reaching beyond the above processes

\begin{tabular}{lccr}
\multicolumn{2}{l}{$\begin{array}{l}\text { Table 2. Relationships between symbols, sanen perspective and goun. } \\
\text { Icon }\end{array}$ Koen } & Heien & Shinen \\
\hline Rock & Jyu & Sou & Siki \\
Mountain & Jyu & Gyou & Siki \\
Moon & Siki & Jyu & Shiki
\end{tabular}




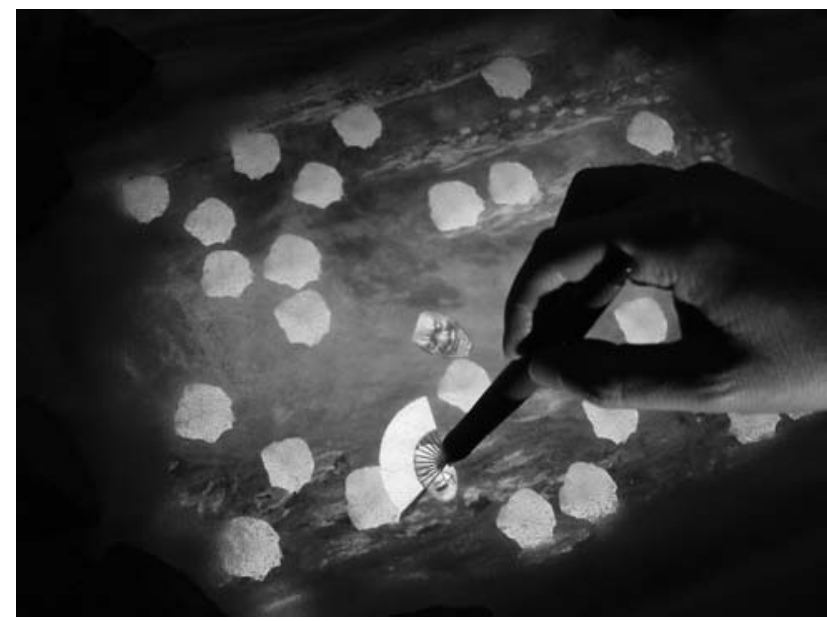

Fig. 8. Zen dialogue "The Lotus Smiles," in which leaves change into petals with successful matching of Noh theater masks. (@) Seigow Matsuoka and Naoko Tosa)

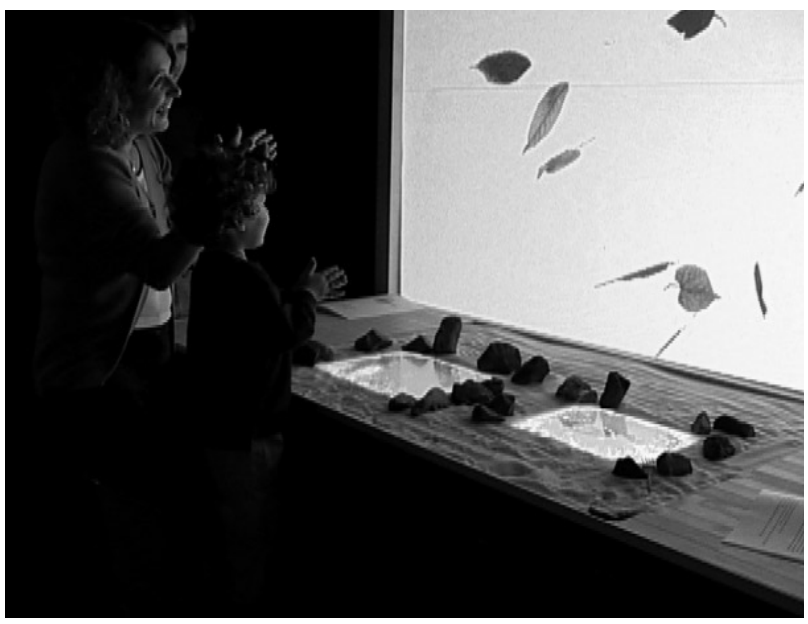

Fig. 9. Zen dialogue "The Sound of One Hand Clapping." (C) Seigow Matsuoka and Naoko Tosa)
The 2D goun space is made up of 10 areas, with the above values along the vertical axis and their strength (positive or negative) along the horizontal axis. When the user generates a sansui landscape according to her preferences, the system classifies the user's individuality through the assignment of goun categories to the icons that make up the landscape (Table 2). Through this process, the user's individuality is expressed as a goun value, and its initial value is determined based on the above categories (Table 3).

\section{Zen Dialogue Interactions}

When the user approaches a certain object within the sansui painting, a Zen event occurs. Every event is constructed such that one can have an interactive vir- tual experience with a Zen koan. The User, Target and Zen Master agents exist within each interaction, and the content of the interaction changes based on their interrelationships.

For example, the koan "Dharma Anjin" (Fig. 7) is a dialogue in which, when a pupil complains, "Even after training, my inner spirit is still troubled," Dharma replies, "Then show me your troubled

\begin{tabular}{|c|c|c|}
\hline Interaction & Goun Input to Target Chaos & Output from User Agent \\
\hline $\begin{array}{l}\text { Dialogue: } \\
\text { "The Catfish and the Gourd" }\end{array}$ & $\begin{array}{l}\text { Change goun depending on part of catfish touched } \\
\text { Touch the head } \rightarrow \text { rise (toward shiki+) } \\
\text { Touch the tail } \rightarrow \text { fall (toward shiki-) }\end{array}$ & Catfish's movement changes \\
\hline $\begin{array}{l}\text { Dialogue: } \\
\text { "The Lotus Smiles" }\end{array}$ & $\begin{array}{l}\text { Goun target changes based on clicks } \\
\text { Sample every time user selects } 2 \text { leaves } \\
\text { If the masks are the same, goun target rises } \\
\text { If the masks are different, goun target falls }\end{array}$ & $\begin{array}{l}\text { Buddha's movement changes } \\
\text { Output audio changes }\end{array}$ \\
\hline $\begin{array}{l}\text { Dialogue: } \\
\text { "Dharma Anjin" }\end{array}$ & $\begin{array}{l}\text { Goun value changes based on drawn lines } \\
\text { Sample data every three seconds } \\
\text { X Axis: Curvature }(0.0 \sim 1.0) \\
\text { Y Axis: Density }(0.0 \sim 1.0)\end{array}$ & Output audio changes \\
\hline Yuzen kimono patterns & $\begin{array}{l}\text { Refer to the goun result of previous four interactions } \\
\text { and select a Japanese cultural form for each. } \\
\text { Mitate: shiki; Kisoi: sou; Soroe: gyou; Awase: jyu, siki }\end{array}$ & $\begin{array}{l}\text { Kimono design is displayed based } \\
\text { on Japanese cultural forms awase, } \\
\text { kisoi, soroe and mitate. }\end{array}$ \\
\hline $\begin{array}{l}\text { Ten Ox Story } \\
\text { Finding the Ox }\end{array}$ & $\begin{array}{l}\text { Change target based on the distance between } \\
\text { first two points drawn (eyes) } \\
\text { Far apart } \rightarrow \text { rise (toward shiki+) } \\
\text { Close together } \rightarrow \text { fall (toward shiki-) }\end{array}$ & None \\
\hline
\end{tabular}




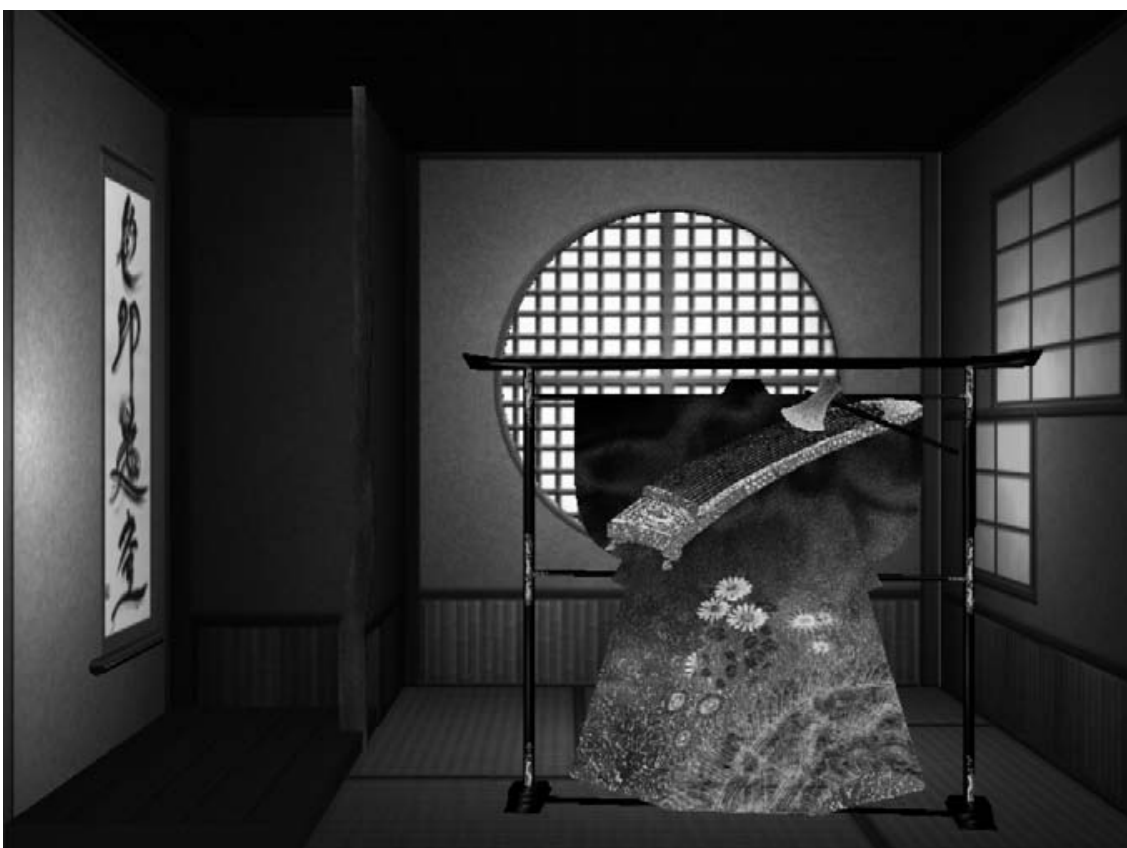

Fig. 10. Example result of Zen dialogue interaction as a kimono pattern. (c) Seigow Matsuoka and Naoko Tosa)

spirit." In this system, we translated this into an interaction in which one draws one's inner spirit. The koan "The Lotus Smiles" (nengemisho), illustrated in Fig. 8, deals with the meaning of telepathy. In order to express this, we created an interaction similar to a card-matching game, hiding Noh Theater masks beneath lotus leaves. The leaves change to flower petals when the user discovers matching masks. Figure 9 shows the koan "The Sound of One Hand Clapping," wherein the system judges the calmness of the user's spirit by measuring the regularity of the user's hand clapping.

\section{Zen Dialogue Interaction Control via Chaos States}

One can think of the interaction in the Zen dialogues as being controlled by a combination of both cooperative and oppositional interactions between three different states: the current state of the user (User), the goal the user should reach (Target), and the Zen master guiding the user (Zen Master). To simulate this process, a model is used such that the reaction of the system during user interactions depends on the interaction of the three elements of User, Target and Zen Master, which are all expressed as points within goun space. In implementing this model, one could envision the positional relationships of the three elements and the system's reactions as a table. However, because with this method the system's reactions become fixed, one cannot realize a framework allowing the enjoyment of different interactions spanning several uses by a single user. In order to allow many users to experience various interactions each time they interact with the system, it is desirable to introduce a suitable "fluctuation."

The system uses a method for the dual synchronization of chaos to realize this fluctuation [12]. The method for dual synchronization of chaos is a model handling the synchronization of two or more chaos states. In this case, we employ a model containing three chaos states, corresponding to the User, Target and Zen Master. Each chaos state corresponds to a point in goun space. Using the method for dual synchronization of chaos, if one applies an initial value and appropriate input values, the three chaos states relate to one another, move through goun space and generate output corresponding to their interactions. For the chaos input, the system uses data from the user's interactions. With the basis of Zen activity, as the axis, the goun value rises the more active a user's interaction is and falls the less active he is.

The output from the chaos model is used after transformation into reaction data for the user of the system. For example, in the "Dharma Anjin" koan, the position of the Target chaos changes depending on the curvature and density of the drawing the user sketches. The higher the density and curvature, the better the goun state achieved. Thus, the
Zen enso (circle) is best. Also, in "The Lotus Smiles," the goun state rises with accuracy in matching images of Noh theater masks. Table 3 shows the rules used for the chaos model and how the system is affected (i.e. the chaos states changed) by the output data.

Finally, depending on the goun result of previous Zen dialogues, a Japanese cultural form represented by a kimono pattern is selected. The patterns are selected based on Japanese aesthetic categories: Mitate: shiki; Kisoi: sou; Soroe: gyou; Awase: jyu and siki, according to Yuzen kimono patterns (Fig. 10).

\section{EVALUATION AND FUTURE PROSPECTS}

In order to see if this system would be accepted by those versed in Buddhism, we had a Tibetan monk and other Buddhists use the system. Receiving an invitation to exhibit our work at Kodai-ji Zen Temple in Kyoto, we accepted an opportunity for a month-long exhibition at the temple in May 2004. The same year, the project was selected for the ACM SIGGRAPH Emerging Technologies exhibition and received recognition as new digital content. Also in 2004, ZENetic Computer received second place in the UNESCO Nabi Digital Storytelling Competition "Intangible Heritage" [13].

As the processing power of computers, high-quality displays and input devices approach the limits of human perception, we expect that high technology will enter the spiritual domain. As seen from the West, Japanese Zen is an old and mysterious philosophy. Indeed, although there are books such as Zen for Dummies, one would be hard pressed to say that it is possible to understand Zen by reading alone. ZENetic Computer tries to convey the spirit of Japanese culture through experiences such as participation in Zen dialogues, exposure to haiku and exploration of kimono patterns. Intercultural understanding is more than just two-way cross-cultural communication.

In the future, there will likely be a strong demand for the conception and design of cultural computing that boldly makes this kind of cross-cultural connection. Everything in this research project was planned with this intent, and for its realization we used leading-edge game design, graphics and interactive displays. It is said that virtual reality would be an appropriate technology for expressing this content. If a technology that can subtly express feelings were joined with VR technology, this combination would be 
even more effective. We are certain that the methods used in ZENetic Computer will flourish in the broad field of education and will make experiential intercultural understanding possible.

\section{References}

1. Bela Balazs, Theory of Film (Tokyo: Gakugeishobo, 1992).

2. K. Isbister et al., "Helper Agent: Designing Assistant for Human-Human Interaction in a Virtual Meeting Space," CHI Letters 2, No. 1, 57-64 (2000).

3. M. Okamoto et al., "Supporting Cross-Cultura Communication with a Large-Screen System," New Generation Computing 20, No. 2, 165-185 (2002).

4. Editorial engineering is a method of improving various processes by editing. It derives from editing representative forms of editing, or editorial forms. It then applies these forms to various activities, such as work, play and adventure. S. Matsuoka, Editorial Engineering of Knowledge (Tokyo: Asahi Shinbunsha, 2001)
5. N. Tosa, Affective Minds (Tokyo: Elsevier, 2000) Chapter 19, pp. 183-201.

6. Janet H. Murray, Digital Storytelling, Tetsuo Arima trans. (Tokyo: Kokubunsya, 2000).

7. <www.astem.or.jp/digital/>.

8. Marc Levoy et al., "The Digital Michelangelo Project: 3D Scanning of Large Statues," Proceedings of SIG ect: 3D Scanning of Large Statues," Proceedings 2000 (August 2000) pp. 131-144.

9. S. Matsuoka, The Science of Natural Beauty (Tokyo: Chuobunko, 2003)

10. S. Matsuoka, Sansui Thought (Tokyo: Gogatsushobo, 2003).

11. Yuzen dyeing was established about 300 years ago, when hand-painted patterns were transferred to silk fabrics for the first time in Japan. Yuzen dyeing enabled fabrics to be dyed in refreshingly variegated colors.

12. This technology is used for laser control. For ex ample, individual synchronization of chaos in a pai of lasers is executed by adjusting the optical freuencies for injection locking between the corresponding pairs. See Y. Liu and P. Davis, "Dual Synchronization of Chaos," Physical Review E 61 (2000) pp. R2176-R2179.
13. <http://portal.unesco.org/culture/en/ev. phpURL_ID=1698\&URL_DO=DO_TOPIC\&URL_ SECTION $=201 . h \mathrm{tml}>$

Manuscript received 25 May 2005.

Naoko Tosa is a professor at Kyoto University's Academic Center for Computing and Media Studies. She has received an award for best paper at the IEEE International Conference on Multimedia (1996), the 14th Telecommunications Advancement Foundation Award (1999) and the Ars Electronica Interactive Art Distinction Award (2000).

Seigow Matsuoka is director of the Editorial Engineering Laboratory, the president of ISIS Editorial School and project leader of the National Institute of Information and Communication Technology. He specializes in editorial engineering, Japanese culture and information culture. He has received the Japanese Cultural Design Award. 